\title{
The 2009 L'Aquila earthquake (central Italy): A source mechanism and implications for seismic hazard
}

\author{
R. J. Walters, ${ }^{1}$ J. R. Elliott, ${ }^{1}$ N. D’Agostino, ${ }^{2}$ P. C. England, ${ }^{1}$ I. Hunstad, ${ }^{2}$ J. A. Jackson, ${ }^{3}$ \\ B. Parsons, ${ }^{1}$ R. J. Phillips, ${ }^{4}$ and G. Roberts ${ }^{5}$ \\ Received 26 May 2009; revised 6 July 2009; accepted 7 August 2009; published 5 September 2009.
}

[1] We use InSAR and body-wave seismology to determine independent source parameters for the 6th April $2009 \mathrm{M}_{\mathrm{w}}$ 6.3 L'Aquila earthquake and confirm that the earthquake ruptured a SW-dipping normal fault with $\sim 0.6-0.8 \mathrm{~m}$ slip. The causative Paganica fault had been neglected relative to other nearby range-frontal faults, partly because it has a subdued geomorphological expression in comparison with these faults. The L'Aquila earthquake occurred in an area with a marked seismic deficit relative to geodetically determined strain accumulation. We use our source model to calculate stress changes on nearby faults produced by the L'Aquila earthquake and we find that several of these faults have been brought closer to failure. Citation: Walters, R. J., J. R. Elliott, N. D'Agostino, P. C. England, I. Hunstad, J. A. Jackson, B. Parsons, R. J. Phillips, and G. Roberts (2009), The 2009 L'Aquila earthquake (central Italy): A source mechanism and implications for seismic hazard, Geophys. Res. Lett., 36, L17312, doi:10.1029/2009GL039337.

\section{Introduction}

[2] On the 6th April 2009, a $\mathrm{M}_{\mathrm{w}} 6.3$ earthquake caused significant damage to L'Aquila, the medieval capital city of the Abruzzo region of Italy, and several surrounding towns and villages (Figure 1). 297 people were killed, 1,000 injured, 66,000 made homeless, and many thousands of buildings were destroyed or damaged. Initial fault plane solutions published by the Global Centroid Moment Tensor Project (gCMT, www.globalcmt.org) for the main shock and aftershocks are consistent with predominantly normal-faulting mechanisms striking NW-SE, with a minor right-lateral component. In this study we use SAR interferometry and body wave seismology to constrain the earthquake source parameters, and use remote sensing and field observations along with static stress models to examine the implications of this earthquake for continuing seismic hazard in the region.

\footnotetext{
${ }^{1}$ COMET, Department of Earth Sciences, University of Oxford, Oxford, UK.

${ }^{2}$ Centro Nazionale Terremoti, Istituto Nazionale di Geofisica e Vulcanogia, Rome, Italy.

${ }^{3}$ COMET, Department of Earth Sciences, University of Cambridge, Cambridge, UK.

${ }^{4}$ School of GeoSciences, University of Edinburgh, Edinburgh, UK

${ }^{5}$ Research School of Earth Sciences, University College London, London, UK.
}

Copyright 2009 by the American Geophysical Union. 0094-8276/09/2009GL039337\$05.00

\section{Determination of Fault Geometry From InSAR Data}

[3] Repeated radar acquisitions covering the epicentral region are available for two Envisat tracks with ascending and descending viewing geometries (see auxiliary material, Table S1). ${ }^{6}$ The InSAR data were processed from raw data products (provided free of charge by ESA as part of the L'Aquila dataset package) using the JPL/Caltech ROI_PAC software [Rosen et al., 2004]. The interferograms were corrected for differences in satellite position using preliminary DORIS satellite orbits from the European Space Agency (ESA). Effects of topography were removed from the interferograms using a 3-arc-second $(\sim 90 \mathrm{~m})$ resolution Shuttle Radar Topography Mission (SRTM) Digital Elevation Model (DEM) [Farr et al., 2007].

[4] The ascending track interferogram shows only one clear lobe of deformation, while the descending track interferogram shows asymmetric, two-lobe, deformation (Figure 2). The gradients of line-of-sight (LOS) deformation within the hanging-wall lobe are asymmetric in both interferograms, showing the greatest gradients on the NE area of the lobe. This asymmetry, and the two-lobe pattern seen in the descending track data, are qualitatively consistent with a normal fault striking $\sim \mathrm{NW}-\mathrm{SE}$ and dipping to the SW. Peak deformation in both interferograms is $\sim 25 \mathrm{~cm}$ LOS motion away from the satellite, and we interpret this as subsidence in the hanging-wall. Areas of incoherence relate to vegetated regions and snow in areas of high topography.

[5] The unwrapped interferograms were downsampled with a quadtree algorithm [e.g., Jonsson et al., 2002], reducing the number of data points for each interferogram from several million to $\sim 750$ (see auxiliary material, Figure S1). The subsampled data sets were jointly inverted for uniform slip on a rectangular fault plane in an elastic half-space [Okada, 1985], using a Powell optimization algorithm with multiple Monte Carlo restarts to find the best-fitting combination of fault parameters [e.g., Wright et al., 2003]. We neglect the postseismic deformation contribution in the period covered by the interferograms, as measurements taken from permanent GPS stations suggest that this contribution is at most $\sim 7 \%$ of the mainshock moment release (D. Cheloni et al., manuscript in preparation, 2009), equivalent to less than one fringe.

[6] In the uniform-slip solution (Table 1), the causative fault strikes approximately NW-SE and dips $54^{\circ}$ to the SW. Slip on the fault is largely normal dip-slip with a small

\footnotetext{
${ }^{6}$ Auxiliary materials are available in the HTML. doi:10.1029/ 2009 GL039337.
} 

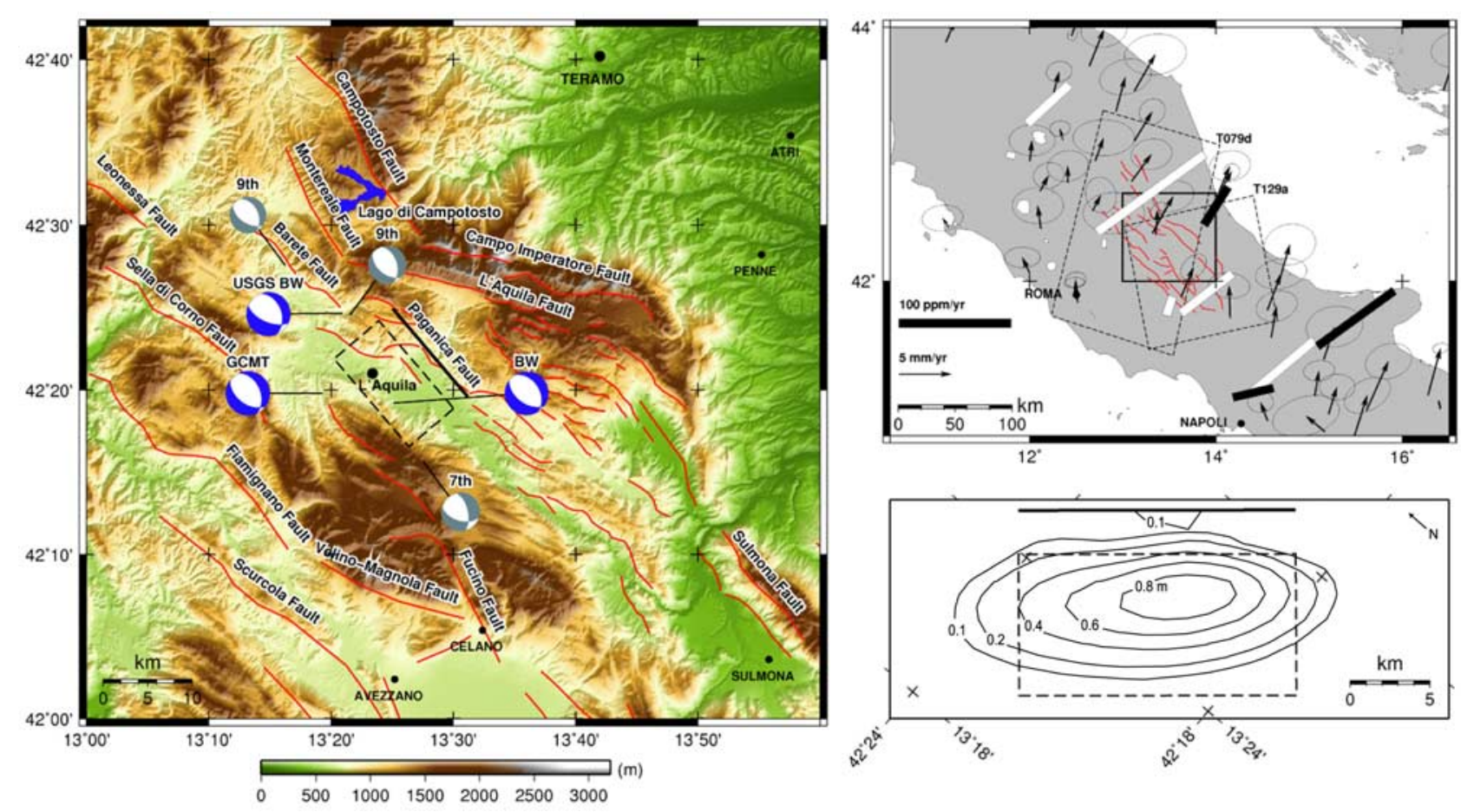

Figure 1. (left) Shaded relief elevation map of the L'Aquila region, central Italy. The gCMT and USGS body wave focal mechanisms for the main earthquake on 6th April are indicated in blue, along with the solution from body wave modelling in this study (BW). gCMT solutions for aftershocks on the 7th and 9th April are shown in grey. Locations of earthquakes are shown by black lines leading from the focal mechanisms. The up-dip surface projection of the causative fault from our uniform-slip InSAR solution (Figure 2 and Table 1) is shown in black, with the black dashed box showing the outline of the fault. Previously mapped faults are marked by red lines and are digitised from Tondi [2000], Roberts and Michetti [2004], and D'Agostino et al. [2001] and interpretation of the SRTM DEM. (top right) Region of study within central Italy (black box), with area covered by SAR interferometry shown by the dashed boxes for descending track 079 and ascending track 129. GPS vectors and associated error ellipses indicate motion relative to a fixed Eurasia reference frame from D'Agostino et al. [2008], and positive (white bars) and negative (black bars) shear strain rates are from Hunstad et al. [2003], showing active extension concentrated along the axis of the Apennines. Previously mapped faults are simplified from those shown in Figure 1 (left). (bottom right) Enlarged map of the fault area. Black dashed box is the same as in Figure 1 (left), and contours show the surface projection of slip contours from our distributed-slip model (Figure S5).

component of right-lateral strike-slip. Root-mean-square (RMS) misfit values for each data set to the model are around $1 \mathrm{~cm}$ (Figure 2). To provide independent constraints for the event source parameters, we also model teleseismic long-period waveforms (Figure S2), and have mapped surface ruptures in the field in the weeks following the earthquake. The body-wave results support our InSAR model, as do the gCMT and USGS solutions, but there is one significant discrepancy between our solution and the seismology (Table 1). The seismological models for the earthquake have strikes in the range $122-127^{\circ}$ for the fault plane, whilst our InSAR model suggests the plane strikes at $144^{\circ}$. However, if we model the body-wave data with the strike fixed at $144^{\circ}$, the change in strike is compensated for by a change in rake. The fit to the data is not degraded by a significant amount (Figure S3), suggesting that the seismological constraint on the strike may be weaker than that from InSAR.

[7] In addition, analysis of geomorphology using satellite imagery (Figure 3 ) gives a strike in the range $140-145^{\circ}$, strongly supporting the strike inferred by our InSAR model. The surface ruptures we mapped in the field also coincide with the geomorphological fault trace.
[8] The data were also inverted for variable slip on an array of rectangular fault patches (see Figure S5 for model and residual interferograms and details of the inversion). The results of this model are shown in Table 1. The fit to the data is significantly improved and the overall RMS misfit is reduced from $1.1 \mathrm{~cm}$ to $0.9 \mathrm{~cm}$. Figure 1 shows that this model predicts surface ruptures of $\sim 10 \mathrm{~cm}$ along a $3 \mathrm{~km}$ section of the fault. The location and magnitude of surface ruptures that we mapped in the field agree very well with this prediction.

\section{Implications for Seismic Hazard}

[9] The surface projection of the model fault coincides with the trace of the Paganica fault (Figure 3). Whilst Boncio et al. [2004] suggest the Paganica fault as the source of large earthquakes in 1461 and 1762, other authors, e.g., D'Agostino et al. [2001], have regarded the fault as less recently active than other faults in the region. This is partly because its surface trace is marked by relatively subtle changes in slope and incision, and unlike many other faults in this region, e.g., the L'Aquila (also Assergi) and Campo Imperatore faults to the NE (the Gran Sasso Fault system), 

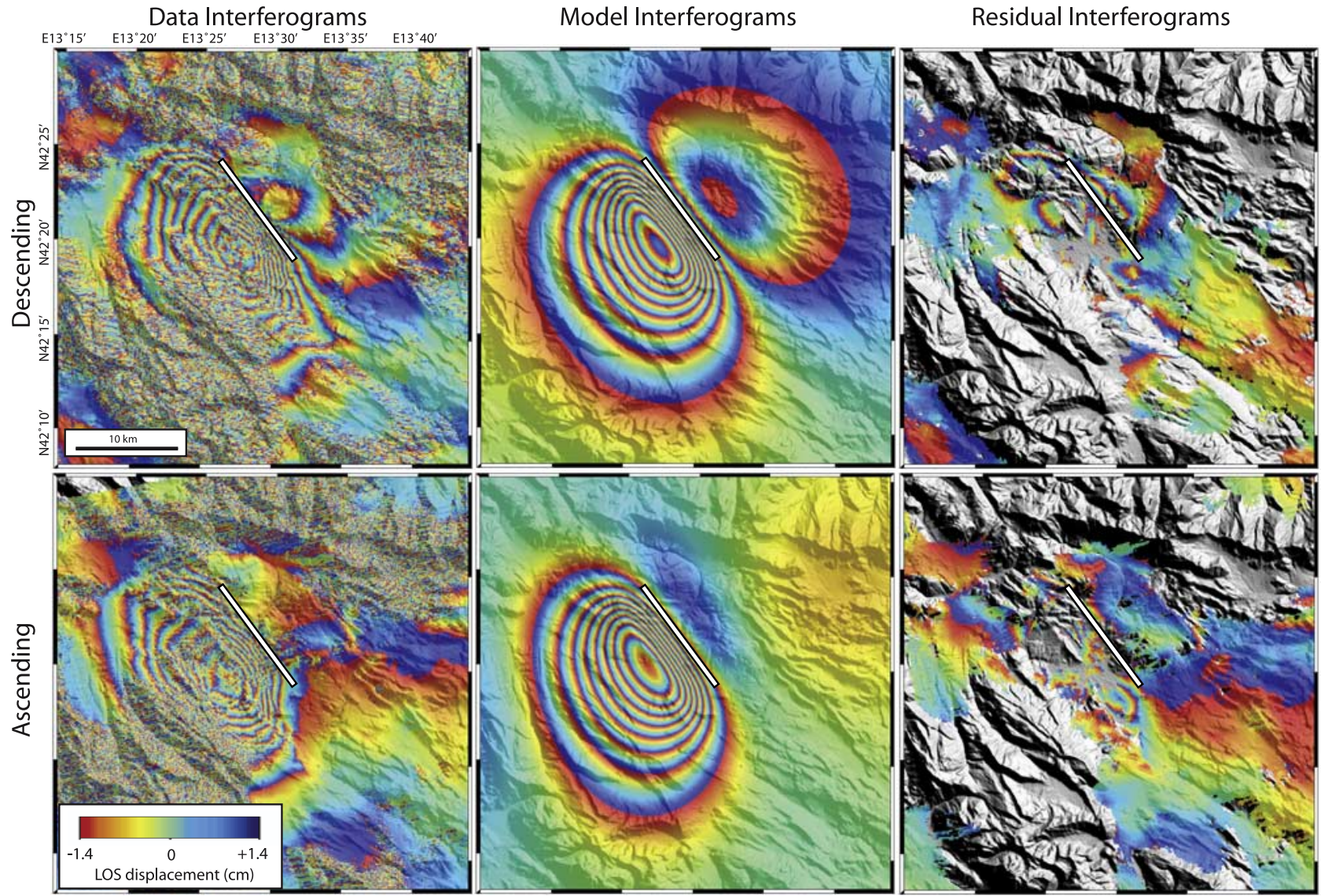

Figure 2. (left) Data, (middle) model, and (right) residual interferograms for Envisat (top) descending track 079, dates 090201-090412 and (bottom) ascending track 129, dates 090311-090415, with the fault rupture modelled as a uniform dislocation in an elastic medium. The white line in the interferograms is the up-dip surface projection of our model fault plane. All interferograms are overlain on SRTM topography illuminated from the NE. RMS misfit values for descending and ascending uniform slip models are 1.2 and $1.0 \mathrm{~cm}$ respectively.

the fault does not bound a steep-fronted mountain range (Figure 3, top right).

[10] Bagnaia et al. [1992] identified the Paganica fault as a late-Quaternary fault, and pointed out that its footwall is an incised late-Quaternary surface. We suggest that the fault system here bears a similarity to the Locris half graben on the south coast of the Gulf of Evvia, Central Greece, wherein active faulting lifts up the syn-tectonic sediments that lie in the hanging-wall of older faults [Goldsworthy and Jackson, 2001]. In contrast with the Paganica fault, the L'Aquila and Campo Imperatore faults have not produced any historical earthquakes, despite paleoseismological evidence for pre-historic ruptures [Giraudi and Frezzotti, 1995; Galli et al., 2002].

[11] It is important for hazard assessment to identify which other faults in the L'Aquila area may have been

Table 1. Source Parameters for the L'Aquila Earthquake From Various Sources

\begin{tabular}{|c|c|c|c|c|c|c|c|c|c|c|c|c|}
\hline Model $^{\mathrm{a}}$ & Strike $^{\circ}$ & Dip $^{\circ}$ & Rake $^{\circ}$ & Slip m & Lon $^{\mathrm{b}} \circ$ & $\mathrm{Lat}^{\mathrm{b}} \circ$ & Length km & Top km & Bottom km & Centroid km & Moment $\times 10^{18} \mathrm{Nm}$ & $\mathrm{M}_{\mathrm{w}}$ \\
\hline InSAR-u & $\begin{array}{l}144 \\
\pm 1^{\mathrm{c}}\end{array}$ & $\begin{array}{r}54 \\
\pm 1^{\mathrm{c}}\end{array}$ & $\begin{array}{l}-105 \\
\pm 3^{\mathrm{c}}\end{array}$ & $\begin{array}{c}0.66 \\
\pm 0.02^{\mathrm{c}}\end{array}$ & $\begin{array}{c}13.449 \\
\pm 0.1 \mathrm{~km}^{\mathrm{c}}\end{array}$ & $\begin{array}{c}42.333 \\
\pm 0.1 \mathrm{~km}^{\mathrm{c}}\end{array}$ & $\begin{array}{l}12.2 \\
\pm 0.2^{\mathrm{c}}\end{array}$ & $\begin{array}{c}3.0 \\
\pm 0.1^{\mathrm{c}}\end{array}$ & $\begin{array}{l}11.7 \\
\pm 0.3^{\mathrm{c}}\end{array}$ & $\begin{array}{r}7.3 \\
\pm 0.1^{\mathrm{c}}\end{array}$ & $\begin{array}{c}2.80 \\
\pm 0.08^{\mathrm{c}}\end{array}$ & 6.23 \\
\hline InSAR-d & $144^{\mathrm{d}}$ & $54^{\mathrm{d}}$ & $-105^{\mathrm{d}}$ & 0.40 & 13.449 & 42.333 & 19 & 0 & 13 & 7 & 2.91 & 6.24 \\
\hline Body Wave & 126 & 52 & -104 & - & 13.31 & 42.33 & 12 & 0 & 9 & 4 & 3.02 & 6.25 \\
\hline gCMT-Q & 127 & 50 & -109 & - & 13.32 & 42.33 & - & - & - & 12 fixed & 3.42 & 6.29 \\
\hline USGS & 122 & 53 & -112 & - & 13.37 & 42.40 & - & - & - & 10 & 3.4 & 6.29 \\
\hline GPS & 134 & 49 & -100 & 0.72 & 13.47 & 42.36 & 11.1 & 1.5 & 11.8 & 6.7 & 3.73 & 6.31 \\
\hline
\end{tabular}

a gCMT-Q, Quick gCMT; USGS, USGS Centroid Moment Tensor Solution; Body Wave, body waveform model from this study; InSAR-u, uniform elastic dislocation InSAR model, elastic shear modulus $=3.2 \times 10^{10} \mathrm{~Pa}$, Poisson ratio $=0.25$; InSAR-d, distributed-slip InSAR model (approximate fault dimensions defined by the maximum extents of the region within which $95 \%$ of slip occurs, and mean slip is the average slip over this region; GPS, values from D. Cheloni et al. (manuscript in preparation, 2009). Only the west-dipping nodal plane is presented for seismic models, as surface ruptures mapped in the field are located at the NE side of the area of subsidence seen in both interferograms.

${ }^{\mathrm{b}}$ Location given as hypocentre for gCMT and USGS models, and as the fault plane centroid for InSAR models.

${ }^{c}$ Formal $1 \sigma$ errors of model fault parameters determined using a Monte Carlo method [e.g., Wright et al., 2003]. See Figure S4 for full uncertainties and trade-offs.

${ }^{d}$ Values fixed at those from uniform slip model. 

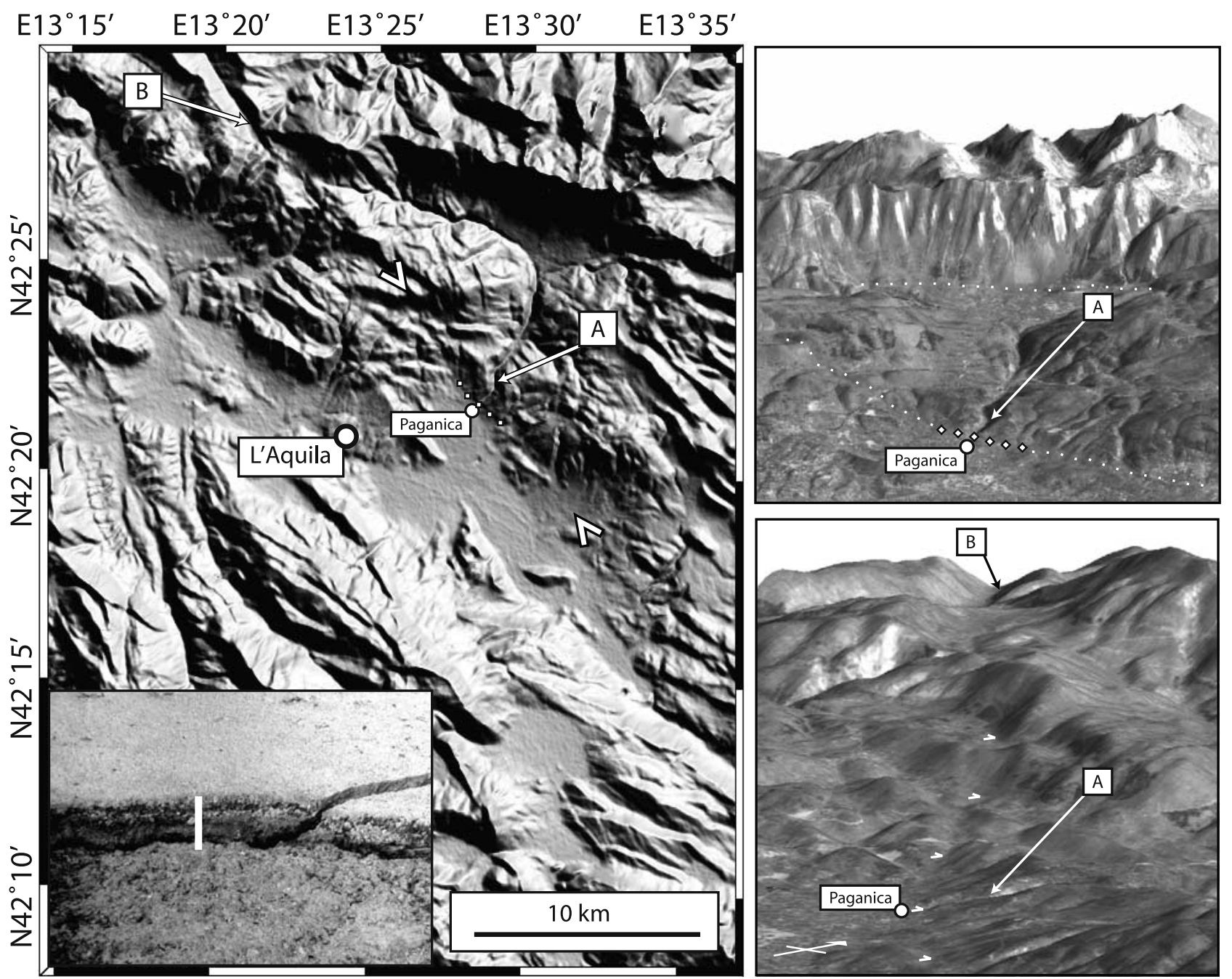

Figure 3. Geomorphology of the Paganica fault and surrounding region. (left) $90 \mathrm{~m}$ SRTM digital topography of the L'Aquila area, illuminated from the NE. The large arrowheads mark the ends of the surface projection of our model fault, and the diamond-dotted line indicates the approximate trace of discontinuous surface ruptures we have mapped in the field. The inset photograph shows a surface rupture with a throw of $\sim 7-10 \mathrm{~cm}$ (white bar $=10 \mathrm{~cm}$ ). (top right) A perspective view looking towards the Paganica fault (near dotted line, with diamond-dotted segment same as in main panel) and L'Aquila fault (far dotted line) using the SRTM DEM overlain with a LANDSAT panchromatic image. (bottom right) A similar perspective view along the Paganica fault from the SE. North arrow in lower left corner. Small white arrows mark the fault; where the fault crosses high topography in the NW it is marked by triangular facets and a change in slope, whilst further to the SW, where the fault crosses lower topography, it is marked by a more subtle change in slope but a clear change in incision. These features can be seen in both the perspective view and in Figure 3 (left). Feature labelled A in Figures 3 (top right) and 3 (bottom right) is a steep gorge cut by a river that crosses the Paganica Fault but is only deeply incising into the uplifting footwall. B is the range front of the SW dipping Montereale fault, which lies along strike to the Paganica fault.

brought closer to failure by stress changes following the L'Aquila earthquake. To this end we examine the changes in Coulomb stress on the array of normal faults in the region resulting from the slip on the Paganica Fault using the Coulomb 3.1 code developed by the USGS [e.g., Lin and Stein, 2004]. The change in Coulomb stress $(\Delta \tau)$ is defined as $\Delta \tau=\Delta \bar{\tau}_{f}+\mu^{\prime} \Delta \sigma_{n}$ [King et al., 1994], where $\bar{\tau}_{f}$ is the change in shear stress on the receiver fault, $\mu^{\prime}$ is the effective co-efficient of friction (incorporating changes in pore pressure) and $\Delta \sigma_{n}$ is the change in the normal stress (positive when unclamped). We assume a value of 0.6 for $\mu^{\prime}$, but calculations with $\mu^{\prime}=0.4$ give similar results. We use a shear modulus of $3.2 \times 10^{10} \mathrm{~Pa}$ to match that used in the InSAR and body wave modelling.

[12] We sample our InSAR distributed-slip fault model (Figure S5) onto an array of $\sim 3 \mathrm{~km}$ patches. Location and strike of nearby faults are calculated using generalised straight segments from the digitised faults shown in Figure 1. We assume a dip of $45^{\circ}$, a rake of $-90^{\circ}$, and a down-dip extent of $15 \mathrm{~km}$ for each fault, and sub-divide them into smaller $\sim 5 \times 5 \mathrm{~km}$ patches in the near-field where stress gradients are largest. The greatest stress increases are seen on the fault patches of the Paganica Fault surrounding those that are modelled as having slipped in the 


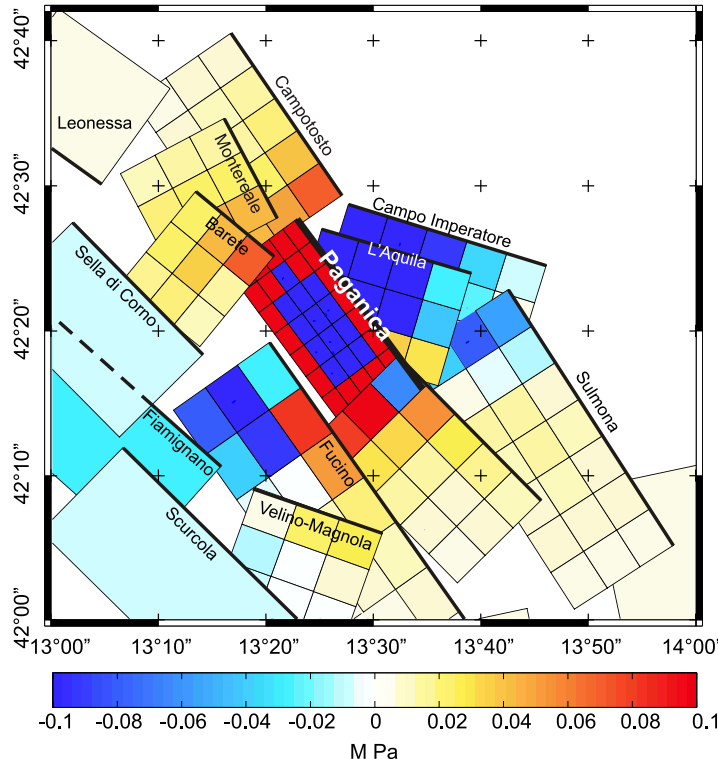

Figure 4. Coulomb stress change on faults surrounding the Paganica fault due to the slip estimated in the 6th April 2009 earthquake from the InSAR distributed slip model. The colour range has been saturated at $\pm 0.1 \mathrm{MPa}$ to highlight the stress change on other faults, but the maximum range is $\pm 0.5 \mathrm{MPa}$ for fault patches on the Paganica fault itself. A map and cross-sections of the Coulomb stress changes calculated for faults in the same orientation as the source fault are shown in Figure S6.

earthquake (Figure 4). Faults parallel to the source fault and offset from it perpendicular to strike generally have reduced Coulomb stresses (in the region of $0-0.1 \mathrm{MPa}$ ), whereas those along strike have increased $(0-0.1 \mathrm{MPa})$ stresses. Of particular interest are the Campotosto and Montereale Faults to the North of L'Aquila in the vicinity of the towns of Campotosto and Amatrice, which have been brought closer to failure with an increase of up to $0.06 \mathrm{MPa}$, decreasing along strike to the north. These two faults are the likely sources of the aftershocks on the 9th April, and the Montereale fault may also represent a NW continuation of the Paganica fault (Figure 3, bottom right and 3, left). In addition, the Campotosto fault runs underneath the dam at the northern end of the reservoir Lago di Campotosto, and this presents a further hazard to be considered in future assessment. Our calculations also suggest that the unnamed fault directly to the SE of the Paganica fault is loaded by the L'Aquila earthquake.

[13] Hunstad et al. [2003] highlighted a significant discrepancy between seismic and geodetic strain rates for the Italian peninsular, and in particular for the L'Aquila region, calculating a seismic strain deficit equivalent to $\mathrm{M}_{0} \sim 23 \times 10^{18} \mathrm{Nm}$. The recent earthquake sequence near L'Aquila can only have reduced this discrepancy by $\sim 3-4 \times$ $10^{18} \mathrm{Nm}$, leaving a significant seismic strain deficit and subsequent earthquake hazard in the region.

\section{Summary}

[14] Interferometry and seismology show that the 2009 L'Aquila earthquake ruptured along a SW-dipping normal fault NE of L'Aquila. These results, along with field and remote sensing observations, have revealed that the earthquake occurred on the Paganica fault, a structure with a weak topographic signature that was thought by some authors to be less active than neighbouring faults. This observation highlights a problem with the identification of potentially dangerous seismogenic faults in this, and similar, tectonic regions.

[15] Static stress calculations show that the earthquake has imparted stress changes on other nearby active faults, bringing several of them, most notably the Montereale and Campotosto faults, closer to failure. The seismic strain deficit in this area was only partially alleviated by the 2009 L'Aquila earthquake sequence and continues to represent a seismic hazard in the region.

[16] Acknowledgments. This work was supported by the Natural Environmental Research Council through the National Centre for Earth Observation, of which the Centre for the Observation and Modelling of Earthquakes, Volcanoes and Tectonics (COMET) is part, as well as through studentships to RJW and JRE, and grants NE/H003266/1 and NE/E01545X/1 to RJP and GR. All Envisat SAR data were provided and copyrighted by the European Space Agency. We are grateful to JPL/Caltech for use of the ROI_PAC software, and to the USGS for use of the Coulomb 3.1 software.

\section{References}

Bagnaia, R., A. D’Epifanio, and S. Sylos Labini (1992), Aquila and Subequan basins: An example of Quaternary evolution in central Apennines, Italy, Quat. Nova, 2, 187-209.

Boncio, P., G. Lavecchia, and B. Pace (2004), Defining a model of 3D seismogenic sources for Seismic Hazard Assessment applications: The case of central Apennines (Italy), J. Seismol., 8, 407-425, doi:10.1023/B:JOSE.0000038449.78801.05.

D’Agostino, N., J. A. Jackson, F. Dramis, and R. Funiciello (2001), Interactions between mantle upwelling, drainage evolution and active normal faulting: An example from the central Apennines (Italy), Geophys. J. Int., 147, 475-497, doi:10.1046/j.1365-246X.2001.00539.x.

D’Agostino, N., A. Avallone, D. Cheloni, E. D'Anastasio, S. Mantenuto, and G. Selvaggi (2008), Active tectonics of the Adriatic region from GPS and earthquake slip vectors, J. Geophys. Res., 113, B12413, doi:10.1029/ 2008JB005860.

Farr, T. G., et al. (2007), The Shuttle Radar Topography Mission, Rev. Geophys., 45, RG2004, doi:10.1029/2005RG000183.

Galli, P., F. Galadini, M. Moro, and C. Giraudi (2002), New paleoseismological data from the Gran Sasso d'Italia area (central Apennines), Geophys. Res. Lett., 29(7), 1134, doi:10.1029/2001GL013292.

Giraudi, C., and M. Frezzotti (1995), Palaeoseismicity in the Gran Sasso Massif (Abruzzo, central Italy), Quat. Int., 25, 81-93, doi:10.1016/10406182(94)P3716-L.

Goldsworthy, M., and J. Jackson (2001), Migration of activity within normal fault systems: Examples from the Quaternary of mainland Greece, J. Struct. Geol., 23, 489-506, doi:10.1016/S0191-8141(00)00121-8.

Hunstad, I., G. Selvaggi, N. D'Agostino, P. England, P. Clarke, and M. Pierozzi (2003), Geodetic strain in peninsular Italy between 1875 and 2001, Geophys. Res. Lett., 30(4), 1181, doi:10.1029 2002 GL016447.

Jonsson, S., H. Zebker, P. Segall, and F. Amelung (2002), Fault slip distribution of the $M_{w} 7.2$ Hector Mine earthquake estimated from satellite radar and GPS measurements., Bull. Seismol. Soc. Am., 92, 1377-1389, doi: $10.1785 / 0120000922$

King, G. C. P., R. S. Stein, and J. Lin (1994), Static stress changes and the triggering of earthquakes, Bull. Seismol. Soc. Am., 84, 935-953.

Lin, J., and R. S. Stein (2004), Stress triggering in thrust and subduction earthquakes and stress interaction between the southern San Andreas and nearby thrust and strike-slip faults, J. Geophys. Res., 109, B02303, doi:10.1029/2003JB002607.

Okada, Y. (1985), Surface deformation due to shear and tensile faults in a half-space, Bull. Seismol. Soc. Am., 75, 1135-1154.

Roberts, G., and A. M. Michetti (2004), Spatial and temporal variations in growth rates along active normal fault systems: An example from the Lazio Abruzzo Apennines, central Italy, J. Struct. Geol., 26, 339-376, doi:10.1016/S0191-8141(03)00103-2

Rosen, P. A., S. Henley, G. Peltzer, and M. Simons (2004), Updated Repeat Orbit Interferometry package released, Eos Trans. AGU, 85(5), doi:10.1029/2004EO050004. 
Tondi, E. (2000), Geological analysis and seismic hazard in the central Apennines (Italy), J. Geodyn., 29, 517-533, doi:10.1016/S02643707(99)00048-4.

Wright, T. J., Z. Lu, and C. Wicks (2003), Source model for the $M_{w} 6.7,23$ October 2002, Nenana Mountain earthquake (Alaska) from InSAR, Geophys. Res. Lett., 30(18), 1974, doi:10.1029/2003GL018014.

N. D'Agostino and I. Hunstad, Centro Nazionale Terremoti, Istituto Nazionale di Geofisica e Vulcanogia, Via di Vigna Murata 605, I-00143 Rome, Italy.
J. R. Elliott, P. C. England, B. Parsons, and R. J. Walters, COMET, Department of Earth Sciences, University of Oxford, Parks Road, Oxford OX1 3PR, UK. (richard.walters@earth.ox.ac.uk)

J. A. Jackson, COMET, Department of Earth Sciences, University of Cambridge, Madingley Road, Cambridge CB3 0EZ, UK

R. J. Phillips, School of GeoSciences, University of Edinburgh, Drummond Street, Edinburgh EH8 9XP, UK

G. Roberts, Research School of Earth Sciences, University College London, Gower Street, London WC1E 6BT, UK. 